\title{
PRENATAL DIAGNOSIS BY ULTRASOUND IN PREGNANCIES AT RISK FOR AUTOSOMAL RECESSIVE POLYCYSTIC KIDNEY DISEASE
}

\author{
Annette Reuss ${ }^{\dagger}$ J. W. Wladimiroff ${ }^{\dagger}$ Patricia A. Stewart ${ }^{\dagger}$ \\ and MARTINUS F. NIERMEIJER ${ }^{\ddagger}$ \\ ${ }^{\dagger}$ Department of Obstetrics \& Gynecology and ${ }^{\ddagger}$ Department of Clinical Genetics, University Hospital Dijkzigt, \\ Erasmus University Rotterdam, Rotterdam, The Netherlands
}

(Received in first and final form 18 August 1989)

\begin{abstract}
In 15 pregnancies at risk of the autosomal recessive type of polycystic kidney disease (ARPKD), there were six recurrences $(40 \%)$, five of which were diagnosed prenatally between 17 and 26 weeks (mean, 22 weeks). In the remaining affected case, normal kidney size and echogenicity were still present at 30 weeks of gestation. Fetal kidney enlargement and increased echogenicity are the key ultrasonographic signs for the detection of ARPKD. Absent fetal bladder filling and oligohydramnios were only documented in two of the six affected pregnancies. The variability in onset, the intrafamilial variability and the limitations of excluding ARPKD by second trimester ultrasound have to be considered when counselling a couple at risk for this particular disorder.
\end{abstract}

Key Words: Autosomal recessive polycystic kidney disease, Prenatal ultrasound, Fetal renal malformations.

\section{INTRODUCTION}

The estimated incidence of autosomal recessive polycystic kidney disease (ARPKD) is about 1:40.000 (Zerres et al. 1984). ARPKD is characterized by cystic dilatation of different proportions of the renal collecting ducts invariably associated with congenital hepatic fibrosis (Potter 1972). Qualitative variation in tubular dilatation allows the distinction of a perinatal group (most common, $>90 \%$ of tubules affected), a neonatal group ( $60 \%$ of tubules affected), an infantile group (25\% of tubules affected) and a juvenile group ( $<10 \%$ of tubules affected), with hepatic fibrosis increasing with prolonged survival in cases of mild renal changes (Blyth and Ockenden 1971; Zerres et al. 1984). In the perinatal group, respiratory insufficiency related to kidney enlargement and lung hypoplasia is the most common cause of death. Renal failure and portal hypertension occur in the neonatal and juvenile group. Although kidneys in ARPKD are often grossly enlarged at birth, prenatal sonographic diagnosis of this entity is not always possible (Zerres

Correspondence address: J. W. Wladimiroff, M.D., Ph.D. Professor of Obstetrics \& Gynecology, Academic Hospital Rotterdam-Dijkzigt, Erasmus University Rotterdam, Dr. Molewaterplein 40, 3015 GD Rotterdam, The Netherlands. et al. 1988). This communication reports on our experience in prenatal sonographic diagnosis of ARPKD in a high-risk population.

\section{PATIENTS AND METHODS}

Between January 1980 and January 1988, a total of 15 pregnancies from seven families at risk for ARPKD was referred to our ultrasound department. In each family at least one earlier affected infant with ARPKD was born. Nearly all of the live-born affected infants died within $6 \mathrm{~h}$ after delivery, only two died at the age of 5 and 7 months. The final diagnosis was made at patho-anatomical examination.

Three couples were consanguineous. The number of pregnancies per family studied varied from 1 to 5. The sonographic examinations were performed using a real-time mechanical sector scanner with a 5-MHz transducer (Diasonics Cardio Vue 100). Each examination included measurement of kidney size, study of the echogenicity of the renal parenchyma, and a careful search for nonrenal defects. Individual values for kidney length were related to the normal range for this parameter according to Jeanty et al. (1982). The presence or absence of oligohydramnios and fetal urinary bladder filling was also documented. A recurrence was diagnosed in the presence 
of enlarged fetal kidneys with the typical hyperechogenic texture (Fig. 1). In all cases follow-up was available. Autopsy was carried out in three of six cases with fetal or neonatal death. All live-born infants were seen by a pediatrician, with a follow-up period varying from 10 months to 7 years.

\section{RESULTS}

Tables 1 and 2 present the prenatal and postnatal findings in all 15 pregnancies. A first ultrasound examination was performed between 17 and 21 weeks of gestation in 11 pregnancies, at 23 weeks in 3 pregnancies and at 26 weeks in the remaining pregnancy. A recurrence of ARPKD was established in 5 out of 15 pregnancies. Gestational age at the time of detection ranged between 17 and 26 weeks (mean, 22 weeks). At the time of diagnosis, all five affected pregnancies displayed enlarged fetal kidneys with increased echogenicity. Normal urinary bladder filling was observed in three and a normal amount of amniotic fluid was documented in four out of five pregnancies. Associated hydrocephaly was diagnosed in one case (no. IV, 7).

Termination of pregnancy was requested in two cases before 24 weeks of gestation. Of the remaining three affected pregnancies which were continued, one was regularly scanned in our unit. In this particular case (no. IV, 4; Table 1), there was renal enlargement, increased echogenicity of the renal parenchyma and absence of bladder filling at 22 weeks; oligohydramnios had only developed at 28 weeks. These three affected pregnancies delivered spontaneously at 36-37 weeks. Neonatal death from respiratory insufficiency occurred in each instance. Permission for autopsy was only given in two (no. III, 5; no. IV, 7) out of these five affected pregnancies. In both cases, mildly enlarged kidneys with cystic dilatation of the collecting tubules were documented. Normal calyces, pyela and ureters were present. The bladder was small. Histology of the liver demonstrated periportal fibrosis and bile duct proliferation. One fetus (no. III, 5) displayed multiple small cysts in the pancreas. In the other case (no. IV. 7), the prenatal diagnosis of associated hydrocephaly was confirmed. Both fetuses had low set ears. There were no signs of lung hypoplasia.

A distended abdomen with a palpable mass in both flanks was noted in the remaining three affected infants in which no autopsy was permitted (nos. IV, $4 ; \mathrm{V}, 3$; VII, 14).

Normal prenatal ultrasound findings of the fetal kidneys were present in 10 out of 15 pregnancies. Serial scans were carried out in all 10 cases, 7 of

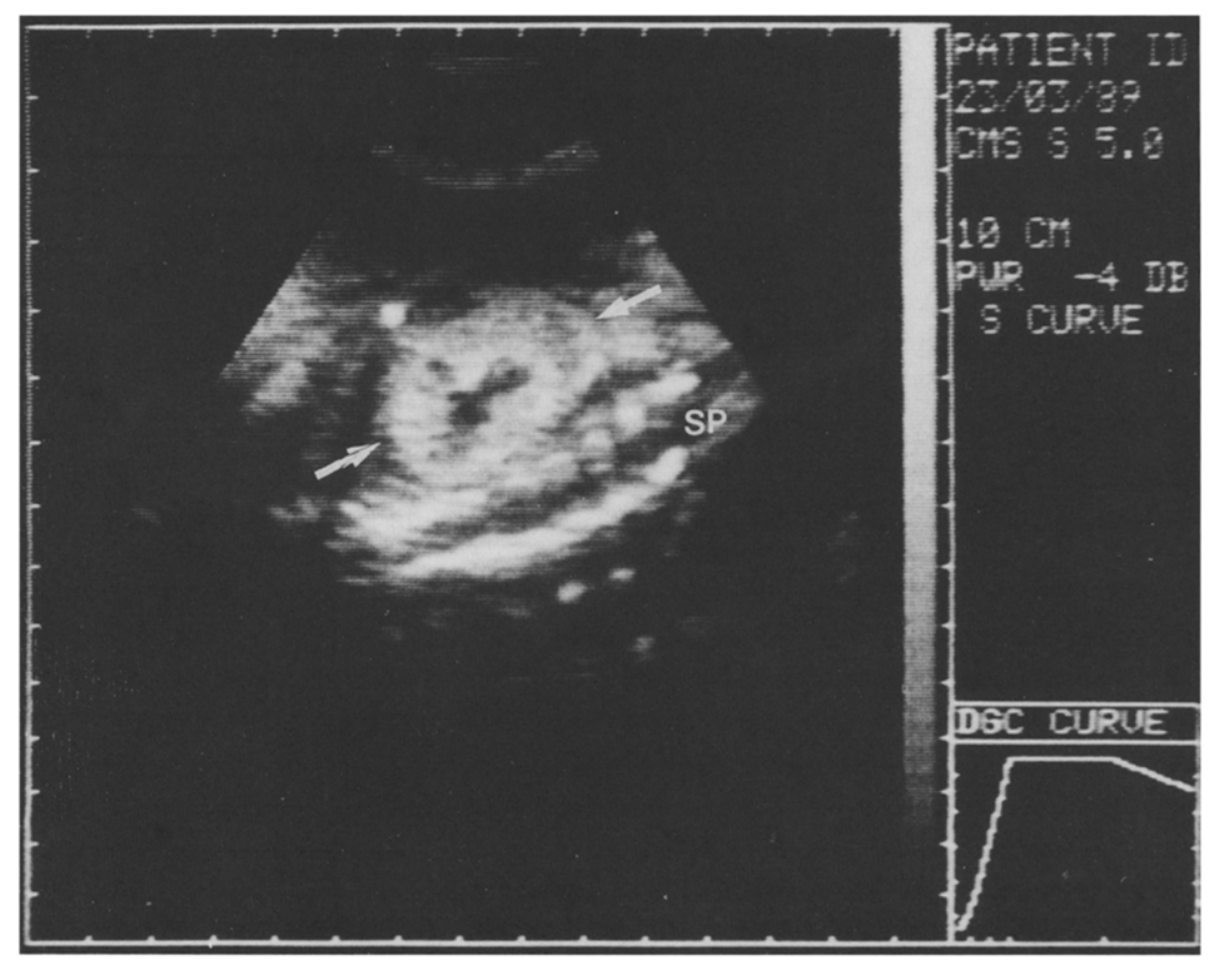

Fig. 1. Longitudinal scan of a fetus with ARPKD at 23 weeks. The kidney displays increased echogenicity; kidney length is situated on the 95 th percentile of the reference curve according to Jeanty et al. (1982). SP = spine. Amniotic fluid volume and bladder filling were normal. 
Table 1. Prenatal renal findings in 15 pregnancies from seven families at risk of ARPKD.

\begin{tabular}{|c|c|c|c|c|c|c|}
\hline $\begin{array}{l}\text { Pat. } \\
\text { no. }\end{array}$ & $\begin{array}{c}\text { Pregnancy } \\
\text { no. }\end{array}$ & Consanguinity & $\begin{array}{c}\text { Gest. age (wks) } \\
\text { at recurrence }\end{array}$ & $\begin{array}{c}\text { Renal } \\
\text { enlargement }\end{array}$ & $\begin{array}{c}\text { Increased } \\
\text { echogenicity }\end{array}$ & Postnatal findings \\
\hline I & $\begin{array}{l}2 \\
3\end{array}$ & $\begin{array}{l}+ \\
+\end{array}$ & - & - & - & $\begin{array}{l}A \& W \\
A \& W\end{array}$ \\
\hline II & 2 & - & - & - & - & affected \\
\hline III & $\begin{array}{l}3 \\
4 \\
5\end{array}$ & $\begin{array}{l}+ \\
+ \\
+\end{array}$ & $\frac{-}{23}$ & $\frac{-}{+}$ & $\overline{-}$ & $\begin{array}{l}\text { A \& W } \\
\text { A \& W } \\
\text { affected }\end{array}$ \\
\hline IV & $\begin{array}{l}3 \\
4 \\
5 \\
6 \\
7\end{array}$ & $\begin{array}{l}+ \\
+ \\
+ \\
+ \\
+\end{array}$ & $\begin{array}{l}\overline{22} \\
\overline{17}\end{array}$ & $\begin{array}{l}\frac{-}{+} \\
\frac{-}{+}\end{array}$ & $\begin{array}{l}- \\
+ \\
+\end{array}$ & $\begin{array}{l}\text { A \& W } \\
\text { affected } \\
\text { hydrocephaly } \\
\text { A \& W } \\
\text { affected + hydrocephaly }\end{array}$ \\
\hline $\mathrm{V}$ & $\begin{array}{l}2 \\
3\end{array}$ & $\begin{array}{l}- \\
-\end{array}$ & $\overline{23}$ & - & $\overline{+}$ & $\begin{array}{l}\text { A \& W } \\
\text { affected }\end{array}$ \\
\hline VI & 3 & - & - & - & - & A \& W \\
\hline VII & 14 & - & 26 & + & + & affected \\
\hline
\end{tabular}

$\mathrm{A} \& \mathrm{~W}=$ alive and well.

which were into the third trimester of pregnancy. There was one case of isolated hydrocephaly diagnosed at 16 weeks (no. IV, 5). Pregnancy was terminated and the abnormality confirmed; the kidneys and liver were histologically normal.

The course of the remaining nine pregnancies was uneventful. After delivery, one infant (no. II, 2), who showed negative scans up to 30 weeks, revealed a distended abdomen at postnatal examination, caused by bilaterally enlarged kidneys. A subsequent renal scan showed polycystic kidneys. This female infant is now 3 years old and suffers from hypertension, intercurrent urinary tract infections and renal tubular dysfunction. The remaining eight infants are alive and well, their age varying between 10 months and 7 years.

\section{DISCUSSION}

The principal problems relating to the prenatal diagnosis of ARPKD are the variability in onset and the limitation of excluding the disease with certainty

Table 2. Prenatal extrarenal and postnatal findings in 15 pregnancies from seven families at risk of ARPKD.

\begin{tabular}{|c|c|c|c|c|c|}
\hline $\begin{array}{l}\text { Pat. } \\
\text { no. }\end{array}$ & $\begin{array}{c}\text { Pregnancy } \\
\text { no. }\end{array}$ & $\begin{array}{l}\text { No bladder } \\
\text { filling }\end{array}$ & Oligohydramnios & $\begin{array}{c}\text { Other } \\
\text { anomalies }\end{array}$ & $\begin{array}{l}\text { Postnatal } \\
\text { findings }\end{array}$ \\
\hline VII & $\begin{array}{l}2 \\
3\end{array}$ & - & - & - & $\begin{array}{l}\text { ?, A \& W } \\
\text { \&, A \& W }\end{array}$ \\
\hline II & 2 & - & - & - & 9, affected \\
\hline III & $\begin{array}{l}3 \\
4 \\
5\end{array}$ & - & - & $\underline{-}$ & $\begin{array}{l}\text { o, A \& W } \\
\text { \&, A \& W } \\
\text { TOP, \&, affected }\end{array}$ \\
\hline IV & $\begin{array}{l}3 \\
4 \\
5 \\
6 \\
7\end{array}$ & $\begin{array}{c}- \\
+(22 \mathrm{wks}) \\
- \\
-\end{array}$ & $\begin{array}{c}- \\
+(28 \mathrm{wks}) \\
- \\
-\end{array}$ & $\frac{-}{\text { hydrocephaly }}$ & 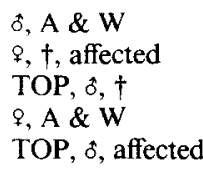 \\
\hline V & $\begin{array}{l}2 \\
3\end{array}$ & - & - & - & $\begin{array}{l}\delta, A \& W \\
\&, \dagger, \text { affected }\end{array}$ \\
\hline VI & 3 & - & - & - & q, A \& W \\
\hline VII & 14 & + & + & - & 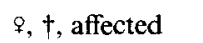 \\
\hline
\end{tabular}

TOP $=$ termination of pregnancy.

A \& $\mathrm{W}=$ alive and well. 
by early pregnancy ultrasound examination (Simpson et al. 1982; Romero et al. 1984; Luthy and Hirsch 1985). Since the disorder does not involve the ureteral bud and affects already well-developed collecting ducts after normal or completed branching, manifestation of ARPKD may not occur early in pregnancy (Zerres et al. 1984, 1988). This must be clearly stated during genetic counselling and may influence the parents' attitude towards the ultrasound examination. One of the couples in our study refused scans during the second half of the second trimester of pregnancy because of potential psychological problems arising from a possible late detection.

In the present study, 6 out of 15 monitored pregnancies $(40 \%)$ displayed a recurrence of ARPKD. Retrospectively, the seven investigated couples had a total of 30 offspring, 14 (47\%) of which were documented to be affected. This latter percentage significantly exceeds the expected $25 \%$ based on a recessive autosomal inheritance pattern $(p<0.05$, binomial test). Prenatal diagnosis of a recurrence of ARPKD was made in five out of six cases, four of which before 24 weeks of gestation. Although autopsy was only carried out in two affected infants, the clinical findings in the remaining three cases were as such that ARPKD could be assumed to be present.

In all five prenatally diagnosed cases, the recognition of ARPKD was based on a combination of renal enlargement and increased parenchymal echogenicity. The echogenicity of the renal parenchyma is increased in both renal cortex and medulla. This hyperechogenic texture is attributed to sound enhancement by the microscopic cystic structures, present in the renal parenchyma.

Oligohydramnios associated with ARPKD has been reported as early as 16-20 weeks of gestation (Morin et al. 1981; Jung et al. 1982; Romero et al. 1984; Luthy and Hirsch 1985; Zerres et al. 1988). On the other hand, normal amounts of amniotic fluid have been described even in cases belonging to the perinatal type (Weiss et al. 1981; Simpson et al. 1982; Romero et al. 1984). Of the six affected pregnancies in our study, only two presented with absent fetal bladder filling and oligohydramnios. In both instances pregnancy had advanced into the second half of the second or early third trimester. Therefore, the prenatal diagnosis of ARPKD should be based on the typical hyperechogenic texture of the kidneys and not, as postulated (Romero et al. 1988), on the presence of oligohydramnios and the absence of bladder filling. The latter two parameters reflect urine production and provide valuable adjunctive information.
When prenatal ultrasound shows the presence of polycystic kidneys, the differential diagnosis should include ARPKD, early manifestation of autosomal dominant polycystic kidney disease and the Meckel Syndrome (Zerres et al. 1984, 1988). A detailed family history and a sonographic search for other manifestations of the Meckel Syndrome, such as polydactyly and encephalocele, should lead to the correct diagnosis. In the present study, patient IV (Table 1) may have been at risk of a separate entity of polycystic kidney syndrome associated with hydrocephaly. Since one male fetus was affected by hydrocephaly only (no. IV, 5) and the other male fetus (no. IV, 7) had hydrocephaly, polycystic kidneys and liver abnormalities, there may have been a risk for two different genetic disorders as a result of consanguinity. Alternatively, X-linked hydrocephaly might be considered as a separate genetic risk in this family. Different expression of one entity can also be considered. Metabolic studies in the index case or affected infant were not performed.

Although the degree of severity of ARPKD is said to be fairly constant within a given family, the possibility of intrafamilial variability has to be borne in mind (Zerres et al. 1984; Kaplan et al. 1988). The variability in time of onset in utero can also be quite considerable within one and the same family (Luthy and Hirsch 1985). Even in case of a proven early ARPKD in a previous infant, a valid and early prenatal diagnostic exclusion by ultrasound in a subsequent pregnancy cannot be guaranteed. Moreover, the disease represents a continuum of renal and hepatic disease rather than precise clinical, pathological and genetic variants.

The variability of ARPKD makes a long-term follow-up of all offspring necessary. In such a followup, emphasis should not only be put on renal function, but should also include possible development of isolated hepatic fibrosis.

In conclusion, recurrence of ARPKD may be diagnosed prenatally by ultrasound, but the variability in onset, the intrafamilial variability and limitations in excluding a recurrence of ARPKD during the second and third trimester of pregnancy remains a difficult problem concerning the reliability of prenatal diagnosis. In the light of the awareness of a highrecurrence risk, all these factors may result in an ambivalent and emotional attitude of couples towards serial ultrasound scanning during pregnancy. This should be kept in mind when genetic counselling is provided.

Acknowledgment-We are grateful to the Clinical Genetics Foundation Rotterdam for their financial support. 


\section{REFERENCES}

Blyth, H.; Ockenden, B. G. Polycystic kidney disease of kidneys and liver presenting in childhood. J. Med. Genet. 8:257-284; 1971.

Jeanty, P.; Dramaix-Wilmet, M.; Elkhazen, N.; Hubinot, C.; van Regemorter, N. Measurement of fetal kidney growth on ultrasound. Radiology 144:159-162; 1982.

Jung, J. H.; Luthy, D. A.; Hirsch, J. H.; Cheng, E. Y. Serial ultrasound of a pregnancy at risk for infantile polycystic kidney disease (IPKD). Birth Defects. Orig. Artic. Ser. 18(3A):173179; 1982.

Kaplan, B. S.; Kaplan, P.; de Chadarevian, J. P.; Jequier, S.; O'Regan, S.; Russo, P. Variable expression of autosomal recessive polycystic kidney disease and congenital hepatic fibrosis within a family. Am. J. Med. Genet. 29:639-647; 1988.

Luthy, D. A.; Hirsch, J. H. Infantile polycystic kidney disease: Observations from attempt at prenatal diagnosis. Am. J. Med. Genet. 20:505-517; 1985 .

Morin, P. R.; Portier, M.; Dallaire, L.; Melancon, S. B.; Boisvert, J. Prenatal detection of the autosomal recessive type of polycystic kidney disease by trehalase assay in amniotic fluid. Prenat. Diagn. 1:75-79; 1981 .
Potter, E. L. Normal and abnormal development of the kidney. Chicago: Year Book Medical Publishers; 1972:141-150.

Romero, R.; Cullen, M.; Jeanty, P.; Grannum, P.; Reece, E. A.; Venus, I.; Hobbins, J. C. The diagnosis of congenital renal anomalies with ultrasound II infantile polycystic kidney disease. Am. J. Obstet. Gynecol. 150:259-262; 1984.

Romero, R.; Pilu, G.; Jeanty, P.; Ghidini, A.; Hobbins, J. C. Infantile polycystic kidney disease. In: Delauter, D. L., ed. Prenatal diagnosis of congenital anomalies. Norwalk, CT: Appleton and Lange; 1988:266-268.

Simpson, J. L.; Sabbagha, R. E.; Elias, S.: Talbot, C.; Tamura, R. K. Failure to detect polycystic kidneys in utero by second trimester ultrasonography. Hum. Genet. 60:295; 1982.

Weiss, H.; Zerres, K.; Hansmann, M. Pränatale Diagnose Zystischer Nierenveränderungen mit Hilfe der Ultraschalltechnik. Ultraschall. 2:244-248; 1981.

Zerres, K.; Völpel, M. C.; Weiss, H. Cystic kidneys. Genetics, pathologic anatomy, and prenatal diagnosis. Hum. Genet. 68:104-135; 1984.

Zerres, K.; Hansmann, M.; Mallman. R.; Gembruch, U. Autosomal recessive polycystic kidney disease. Problems of prenatal diagnosis. Prenat. Diagn. 8:215-229; 1988. 